\title{
Histopathological Changes of Placenta in Meconium Stained Liquor and Its Relevance in Fetal Distress: A Case Control Study
}

\author{
Tanima ROY MONDAL ${ }^{1}$ (D), Goutam BANDYOPADHYAY ${ }^{2}$ (D), Sabuj Ghana MUKHOPADHYAY ${ }^{\text {(D), }}$ \\ Dyuti GANGULY2
}

'Pathologist, MR Bangur Superspeciality Hospital, KOLKATA, WEST BENGAL, INDIA

${ }^{2}$ Department of Pathology, Burdwan Medical College, BURDWAN, WEST BENGAL, INDIA

\begin{abstract}
Objective: Meconium passage during labour is a quite common finding. Studies describing correlation between meconium stained liquor, fetal distress and specific placental pathology are sparse. This case control study had been designed to ascertain these lacunae of knowledge.

Material and Method: Placentae from 41 cases of otherwise uncomplicated antenatal and intranatal pregnancies with meconium stained liquor at 37 completed weeks of gestation were studied, both grossly and microscopically, comparing them with controls of 41 cases of clear liquor. Apgar score of all newborns at 1 minute and 5 minutes were recorded and correlated with histopathological findings.

Results: Both cases and controls were found to be age matched. Meconium stained liquor was associated with more caesarian section than the clear ones. Significant correlation was found with meconium stained liquor and low Apgar scores. Histopathology of placenta revealed many statistically significant associations between specific placental histopathology in meconium stained liquor and depressed Apgar score. Evidence of placental vasculopathy rather than meconium induced placental damage came out as the potential culprit in causing a low Apgar score in this case control study.
\end{abstract}

Conclusion: Placental vascular changes have a role in meconium staining of liquor. If timely interventions are taken, the chance of development of fetal distress is low.

Key Words: Placenta, Histopathology, Meconium stained liquor, Apgar score

\section{INTRODUCTION}

Passage of meconium in-utero is due to bowel peristalsis and relaxation of anal sphincter. Meconium passage is especially common in post-term placentas. It is unlikely to be present before 30 weeks (1). It is considered normal in breech deliveries. In the majority, meconium passage after birth is a sign of physiologic maturity, but it can be associated with fetal distress when seen before delivery. There may be presence of some predisposing factors like maternal hypertension, obstetric cholestasis, multiple pregnancies, and obstructed labour etc. but meconium staining also occurs in many uncomplicated pregnancies and in association with fetal distress, the cause of which is still obscured.

Fetal distress is assessed by the Apgar score (less than 7 at 1 minute and 5 minutes), cardiotocograph traces, and cord or fetal scalp blood pH (less than 7.2) etc. Among these, Apgar score assessment is simple and commonly employed.

(Turk Patoloji Derg 2019, 35:107-118)

Received : 18.05.2018 Accepted : 16.09.2018
Meconium passage has been significantly associated with low Apgar scores, cord blood $\mathrm{pH}$ of 7.0 or less, respiratory distress, seizures in the first 24 hours, and the need for delivery room resuscitation. Neonatal morbidity of all kinds has been significantly associated with meconium stained amniotic fluid as compared to clear amniotic fluid $(1,2)$. Meconium staining of the liquor may be the thin or thick type. Thick meconium is associated with higher morbidity and mortality in comparison to clear liquor (3-5). It is also associated with a higher incidence of emergency caesarean delivery $(4,6,7)$.

Meconium aspiration syndrome is a life-threatening respiratory disease in infants born through meconium stained amniotic fluid. It is associated with thick meconium, low Apgar score and non-reassuring fetal heart rate tracing $(3,8)$. There is some evidence that meconium may interfere with surfactant production and in high enough concentrations, have a direct toxic effect on type

Correspondence: Sabuj Ghana MUKHOPADHYAY

Department of Pathology, Burdwan Medical College

BURDWAN, WEST BENGAL, INDIA

E-mail: iamsabuj@gmail.com Phone: +91 9681003888 
II pneumocytes, possibly contributing to the meconium aspiration syndrome (9). All cases of meconium stained liquor and especially the thick meconium type should therefore be continuously monitored to prevent serious complications (4).

Meconium is thought to cause placental and umbilical cord vasoconstriction along with cerebral and fetal hypoperfusion. These may be the causes for a major poor outcome in meconium stained liquor $(10,11)$. Meconium stained liquor is associated with an increased frequency of chorio-amnionitis (12).

It is not clear that whether meconium staining of liquor is associated with demonstrable placental pathology which may give rise to fetal distress, either directly or indirectly, or whether placental pathology gives rise to meconium staining and in turn causes fetal distress. It is not discernible which is the primary event among these variables.

There are many questions regarding the cause, effect, clinical significance and pathologic expression of in-utero meconium passage which are, as yet, unresolved. In the majority of infants, meconium passage is a reflection of physiological immaturity, although in some, it appears to be associated with adverse stimuli, out of which fetal distress is a significant factor.

It has also been observed that intra-uterine fetal distress is the consequence of maternal and fetal vascular compromise, though the normal placenta has considerable functional reserve. Placental infarct associated with crowding ghost-like villi, fetal thrombotic vasculopathy, intra-villous and peri-villous fibrinoid, placental villous hypoplasia associated with increased inter-villous spaces and exaggerated syncytial knots are some of the pathologic findings associated with fetal and maternal vascular compromise.

It is not certain that such factors, to what extent, are associated with fetal distress and thereby act as potential causes behind the meconium passage in-utero.

There are many studies which describe meconium induced fetal distress. A few studies have described placental changes in meconium stained liquor. However, there are lack of studies describing correlation of placental histopathology with fetal distress in meconium stained liquor.

This study has been undertaken to determine the association between meconium stained liquor with fetal distress and specific placental pathology in such cases. For this purpose, macroscopic and microscopic changes of placentae associated with meconium stained liquor were compared with those in clear liquor in otherwise uncomplicated term pregnancy.

\section{MATERIALS and METHODS}

From $1^{\text {st }}$ January 2016 to $31^{\text {st }}$ December 2016, pregnant mothers in term (37 completed weeks/ 40 completed weeks of gestation) with singleton pregnancy, fetus in cephalic presentation and otherwise with an uncomplicated antenatal and intranatal period and admitted to the G\&O department of the Burdwan Medical college for safe confinement were included in the study. Forty-one cases of meconium stained amniotic fluid were identified. As controls, 41 cases of clear amniotic fluid matching the inclusion criteria were also studied.

The information collected were history \& clinical examination (of the mothers in labour), observation (in the labour room), record review (antenatal card, bed head ticket) and recorded histopathological findings of the placentae.

The parameters were degree of meconium staining (light/ deep), Apgar scores of the newborns, and histopathological changes in placentae of the cases and controls.

After approval from the ethical committee, we attended the labour observation room of Gynaecology \& Obstetrics Dept. of Burdwan Medical College. After duly filling up the consent and case record form (history and clinical examination), inspection of the pregnant mother in term gestation with meconium stained liquor took place and the time of rupture of membrane was noted. Mode of delivery of the case was decided by the obstetricians and delivery was done either by vaginal delivery or caesarean section. We collected the placenta in $10 \%$ buffered formalin solution. Apgar scores of the baby at 1 minute and 5 minutes were recorded. Thus we collected 41 placentae from thin or thick meconium stained liquor cases as per availability of such cases.

We collected 41 placentae with clear liquor after vaginal delivery from age matched control mothers without any antenatal and intranatal complication. We also noted Apgar scores of those newborns at 1 minute and 5 minutes.

Apgar score was determined by noting i) color, ii) respiratory effort, iii) heart rate, iv) muscle tone and v) reflex irritability. Each variable scores 2 points. The cumulative score (maximum being 10 and minimum being 0 ) was graded as follows: No depression (score 7-10); mild depression (score 4- 6); and severe depression (score 0-3)

The color of liquor was graded as- 0 (Clear), 1 (Thin), and 2 (Thick) 
After getting the placentae, gross examinations and procedures were performed; sections were taken from different parts of the fixed placentae after one day and again the sections were fixed in neutral buffered $10 \%$ formalin. Paraffin blocks were prepared after following the routine histopathological techniques. Staining of sections ( $5 \mu$ thick) was done with routine Haematoxylin \& Eosin stain. Light microscopic examination was done and results were noted. Different gross and histopathological changes were recorded in the histopathological data record form. They were corroborated with the respective Apgar score to uncover any relationship between them.

\section{Examination of Placenta}

\section{Macroscopic examination}

Each placenta was examined meticulously as early as possible after collection following delivery and the findings were noted in the case record form. Photographs of the specimen were taken accordingly. The specimen was then placed in 10\% neutral buffered formalin for fixation.

The specimen was examined macroscopically for the following parameters (13):

The size of the placental disc and umbilical cord, shape, weight, colour, fetal surface membrane (graded as 0,1 and 2 according to the intensity of meconium staining), maternal surface, surface vessels and cut surface of the disc and cord.

\section{Microscopic examination}

Seven sections $(14,15)$ were taken for histopathology of placenta including three sections from the disc including fetal and maternal surface, two sections from the fetal membrane (jelly roll technique) and two sections from the umbilical cord. 0

Microscopically, the following parameters were noted.

1. Intervillous space (IVS): It is graded as 0 (narrow IVS), 1 (normal) and 2 (widened IVS )

2. Intravillous fibrinoid and perivillous fibrinoid: In this study, both are graded as 1 (normal), 2 (mild increase) and 3 (marked increase).

3. Villitis: It is graded as 0 (absent) and 1 (present).

4. Syncytial knots (SK): It is increased at term as well as in hypoxic conditions. It is graded as 1 (up to $5 \mathrm{SK} /$ villous in the majority of the villi), 2 (5-10 SK/villous in majority of the villi) and 3 (>10 SK/ villous in the majority of the villi).

5. Calcification: Focal calcification is considered normal at term, but excessive calcification may have underlying pathology. In this study it is graded as 0 (no or focal calcification) and 1 (marked calcification).

6. Infarction: Infarcts are the result of circulatory disturbances. In this study it is graded as 0 (absent) and 1 (present).

7. Fibrosis: Villous stromal fibrosis may occur in hypoxic conditions. It is graded as 0 (absent) and 1 (present).

8. Blood vessel changes: There may be thrombosis/ avascular villi/ atrophy of villi/ fetal thrombotic vasculopathy. In the present study, blood vessel changes are graded as follows: 0 (no change); 1 (mild changes (focal); 2 (marked changes (global)

9. Chorion and amnion: Multilayering of amniotic membrane, ballooning degeneration, necrosis and chorioamnionitis may be present in various proportions in meconium staining. The changes are graded as 0 (absent/ no change) and 1 (present).

10. Umbilical cord: There may be funisitis (inflammation of cord) or cord vasculitis. Changes are graded as 0 (absent) and 1 (present).

11. Chorangiosis: It may be an incidental finding. It is considered when there is presence of more than 10 terminal villi with more than 10 capillaries (actually more than 15 are usually present) involving several areas of placenta. It may be due to abnormal maturation of villi and hypoxia.

At the end of the study, all the data was compiled and tabulated. Analysis was done by using suitable statistical methods (2-tailed t-test and Pearson Chi-square test) and appropriate software (SPSS v.20).

\section{RESULTS}

Minimum maternal age was 19 years and maximum age was 28 years, mean being 23.11 years. The mean age of cases was 23.17 years and of controls was 23.05 years. The difference was not statistically significant. It also proved that the controls were age matched with the cases. The mean gestational age of both cases and controls was 37 weeks. Most mothers were primipara, both in cases and controls.

The mean birth weight of babies of cases was $2818.90 \mathrm{~g}$. and of the controls was $2679.88 \mathrm{~g}$. The difference was statistically significant. Higher birth weight was associated with meconium staining of liquor in comparison to clear liquor.

The meconium stained placenta and placenta with clear meconium was grossly evident (Figure 1,2). 
Table I: The differences in mean, 2 standard deviation, and significance of maternal age, birth weight of babies, placental weight and placental diameter among cases and control group.

\begin{tabular}{|c|c|c|c|c|c|}
\hline Variables & Case & No. & Mean & $2 \mathrm{SD}$ & Significance \\
\hline \multirow{2}{*}{$\begin{array}{l}\text { Maternal age (Yrs.) } \\
(\text { Total }=82)\end{array}$} & Case & 41 & 23.17 & 4.288 & \multirow{2}{*}{0.805} \\
\hline & Control & 41 & 23.05 & 4.604 & \\
\hline \multirow{2}{*}{$\begin{array}{l}\text { Birth weight of baby (Gms.) } \\
\text { (Total=82) }\end{array}$} & Case & 41 & 2818.90 & 282.574 & \multirow{2}{*}{${ }^{\star} 0.001$} \\
\hline & Control & 41 & 2679.88 & 193.074 & \\
\hline \multirow{2}{*}{$\begin{array}{l}\text { Placental weight (Gms.) } \\
\text { (Total=82) }\end{array}$} & Case & 41 & 480.98 & 34.074 & \multirow{2}{*}{${ }^{*} 0.049$} \\
\hline & Control & 41 & 487.32 & 22.034 & \\
\hline \multirow{2}{*}{$\begin{array}{l}\text { Placental diameter }(\mathbf{C m} .) \\
(\text { Total }=82)\end{array}$} & Case & 41 & 20.37 & 2.270 & \multirow{2}{*}{${ }^{\star} 0.040$} \\
\hline & Control & 41 & 19.78 & 2.776 & \\
\hline
\end{tabular}

${ }^{\star}$ Statistically significant (2 tailed t-test).

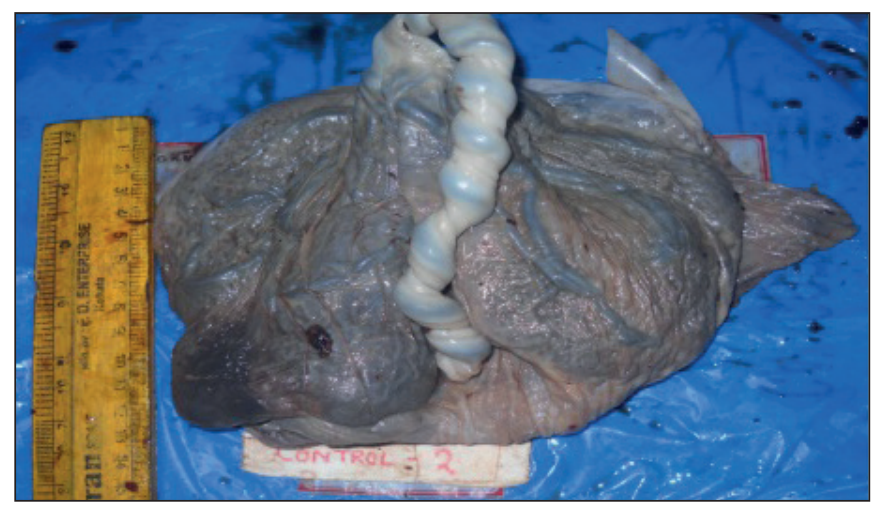

Figure 1: Gross photograph of normal placenta, showing glistening transparent amnion on fetal surface.

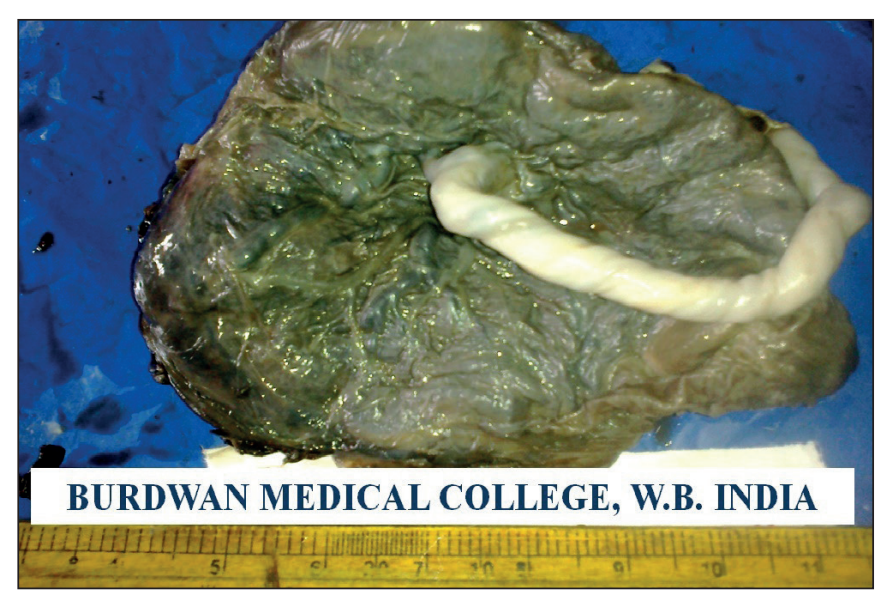

Figure 2: Gross photograph of a meconium stained placenta with opaque, gray-brown fetal surface.

The mean placental weight of cases was $480.98 \mathrm{~g}$. and of controls was $487.32 \mathrm{~g}$. The difference was statistically significant. So, here it was evident that lower weight of placenta was associated with occurrence of meconium staining of liquor (Table I, Figure 3). In this study there was no abnormality noted in maternal surface or cut surface of placenta in either case or control group. No abnormality was

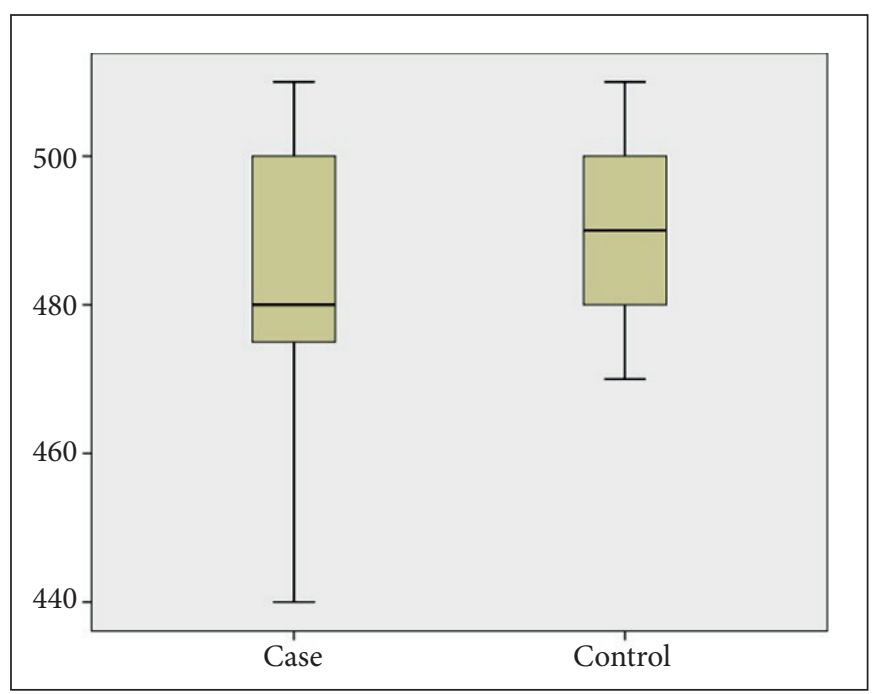

Figure 3: Box whisker showing range of distribution and mean values of placental weight of case and control population $(n=82)$.

seen in gross and microscopical examination of umbilical cord. Among the meconium stained liquor group, 19.6\% $(8 / 41)$ cases had thin and $80.4 \%$ (33/41) cases had thick meconium stained liquor. There was increased incidence of caesarean section in meconium stained liquor group. $29.3 \%(12 / 41)$ newborns were delivered vaginally and $70.3 \%$ (29/41) babies were born through caesarean section.

Salient microscopical findings in this study as observed from different tables and statistical analysis were increase in inter-villous space (19.5\%), prominence of intra(19.5\%) and peri-villous fibrinoid (24.4\%) (Table II), exaggerated syncytial knots (26.8\%), obvious blood vessel changes $(31.7 \%)$, calcification (intra- and peri-villous as well as within vessel wall) (13.4\%) (Table III), villous fibrosis (7.3\%), epithelial hyperplasia in amnion (39\%), evidence of chorio-amnionitis (13.4\%) (Table IV, V). The statistical significance in distinguishing placental changes from normal control was evaluated (Figure 4-9). 
Villitis (6.1\%) and infarction (1.2\%) were observed in this study in variable proportions but not statistically significant.

Villous chorangiosis, a peculiar finding in this study, which was present in $13.4 \%$ of cases, was not statistically significant as it is also observed in control normal placentas (Table V) (Figure 10).
Unlike in previous studies, there was no obvious change in the umbilical cord and rarely meconium laden macrophages in amnion were found in this study.

The Apgar score at 1 minute was as follows: 17.1\% (7/41) were not depressed, even they were associated with meconium stained liquor. Mild depression was present in $60.5 \%(25 / 41)$ and severe depression was noted in $22 \%$

Table II: Evaluation of intervilllous space, intervilllous fibrinoid and perivillous fibrinoid.

\begin{tabular}{|c|c|c|c|c|}
\hline Variables & Cases (\%) & Control (\%) & Total (\%) & p-value \\
\hline \multicolumn{5}{|l|}{ 1. Intervillous space } \\
\hline Narrow & $01(100)$ & $0(0)$ & $01(1.2)$ & \multirow{4}{*}{$\star<0.05$} \\
\hline Normal & $24(36.9)$ & $41(63.1)$ & $65(79.3)$ & \\
\hline Widened & $16(100)$ & $0(0)$ & $16(19.5)$ & \\
\hline Total (\%) & $41(50)$ & $41(50)$ & $82(100)$ & \\
\hline \multicolumn{5}{|l|}{ 2. Intravillous fibrinoid } \\
\hline Normal & $25(37.9)$ & $41(62.1)$ & $66(80.5)$ & \multirow{4}{*}{${ }^{*}<0.05$} \\
\hline Mild increased & $11(100)$ & $0(0)$ & $11(13.4)$ & \\
\hline Marked increased & $05(100)$ & $0(0)$ & $05(6.1)$ & \\
\hline Total (\%) & $41(50)$ & $41(50)$ & $82(100)$ & \\
\hline \multicolumn{5}{|l|}{ 3. Perivillous fibrinoid } \\
\hline Normal & $21(33.9)$ & $41(66.1)$ & $62(75.6)$ & \multirow{4}{*}{${ }^{*}<0.05$} \\
\hline Mild increased & $17(100)$ & $0(0)$ & $17(20.7)$ & \\
\hline Marked increased & $03(100)$ & $0(0)$ & $03(3.7)$ & \\
\hline Total (\%) & $41(50)$ & $41(50)$ & $82(100)$ & \\
\hline
\end{tabular}

^Statistically significant (Pearson’s Chi- square test).

Table III: Depicting incidence of villitis, exaggerated syncytial knots and villous calcification.

\begin{tabular}{|c|c|c|c|c|}
\hline Variables & $\begin{array}{c}\text { Case } \\
\text { Count (\%) }\end{array}$ & $\begin{array}{c}\text { Control } \\
\text { Count }(\%)\end{array}$ & Total (\%) & p-value \\
\hline \multicolumn{5}{|l|}{ 1. Villitis } \\
\hline Absent & $36(46.8)$ & $41(53.2)$ & $77(93.9)$ & \multirow{3}{*}{0.055} \\
\hline Present & $05(100)$ & $0(0)$ & $05(6.1)$ & \\
\hline Total (\%) & $41(50)$ & $41(50)$ & $82(100)$ & \\
\hline \multicolumn{5}{|l|}{ 2. Syncytial knots } \\
\hline Up to 5/ villous & $19(31.7)$ & $41(68.3)$ & $60(73.2)$ & \multirow{4}{*}{${ }^{*}<0.05$} \\
\hline 5- $10 /$ villous & $18(100)$ & $0(0)$ & $18(22)$ & \\
\hline$>10 /$ villous & $04(100)$ & $0(0)$ & $04(4.8)$ & \\
\hline Total (\%) & $41(50)$ & $41(50)$ & $82(100)$ & \\
\hline \multicolumn{5}{|l|}{ 3. Calcification } \\
\hline No/ focal & $30(42.3)$ & $41(57.7)$ & $71(86.6)$ & \multirow{3}{*}{${ }^{* *}<0.05$} \\
\hline Marked increased & $11(100)$ & $0(0)$ & $11(13.4)$ & \\
\hline Total (\%) & $41(50)$ & $41(50)$ & $82(100)$ & \\
\hline
\end{tabular}


(9/41) of cases. Apgar score at 5 minutes after delivery room resuscitation was as follows: No obvious depression in $73.2 \%(30 / 41)$, mild depression in $24.4 \%(10 / 41)$ and severe depression in only $2.4 \%(1 / 41)$ of cases. A significant association was seen between green colored placenta (meconium) and mild depression of Apgar score ( $p$-value $<0.05)$ (statistically significant), when a comparative study was done between the Apgar score and color of the placentas. A widened inter-villous space was significantly associated with mild to severe depression, both at 1 minute and $5 \mathrm{~min}$ ( $\mathrm{p}$-value $<0.01$ ), which was not observed in control cases. Persistent neonatal depression was significantly associated with an increase in the amount of intra-villous and perivillous fibrinoid in the meconium stained liquor group ( $\mathrm{p}$ - value $<0.002$ ).

No significant association was found with presence or absence of villitis, in meconium stained liquor and neonatal depression, evaluated by Apgar score. (p- value >0.094). Exaggerated syncytial knots (Figure 8), though a feature of post-maturity, were also observed in hypoxic state, as revealed from above analysis, showing $\mathrm{p}$-value $<0.05$, which is statistically significant. Wide areas of heterotrophic

Table IV: Incidence of villous infarction, fibrosis and blood vessel change in the study population, compared to control.

\begin{tabular}{|c|c|c|c|c|}
\hline Variables & Case $(\%)$ & Control (\%) & Total (\%) & p-value \\
\hline \multicolumn{5}{|l|}{ 1. Infarction } \\
\hline Absent & $40(49.4)$ & $41(50.6)$ & $81(98.8)$ & \multirow{3}{*}{0.314} \\
\hline Present & $01(100)$ & $0(0)$ & $01(1.2)$ & \\
\hline Total (\%) & $41(50)$ & $41(50)$ & $82(100)$ & \\
\hline \multicolumn{5}{|l|}{ 2. Villous Fibrosis } \\
\hline Absent & $35(46.1)$ & $41(53.9)$ & $76(92.7)$ & \multirow{3}{*}{${ }^{\star} 0.011$} \\
\hline Present & $06(100)$ & $0(0)$ & $06(7.3)$ & \\
\hline Total (\%) & $41(50)$ & $41(50)$ & $82(100)$ & \\
\hline \multicolumn{5}{|c|}{ 3. Blood vessel change } \\
\hline No & $15(26.8)$ & $41(73.2)$ & $56(68.3)$ & \multirow{4}{*}{${ }^{*}<0.05$} \\
\hline Mild & $16(100)$ & $0(0)$ & $16(19.5)$ & \\
\hline Marked & $10(100)$ & $0(0)$ & $10(12.2)$ & \\
\hline Total (\%) & $41(50)$ & $41(50)$ & $82(100)$ & \\
\hline
\end{tabular}

Mild changes in blood vessels were focal narrowing of lumen, while marked changes as observed in this study were obliteration of lumen in wide areas.

* Villous fibrosis and blood vessel changes are statistically significant applying.

Pearson's Chi- square test.

Table V: Depicting changes in Chorion, Amnion and presence of villous chorangiosis as an incidental finding.

\begin{tabular}{|c|c|c|c|c|}
\hline Variables & No of cases (\%) & Control (\%) & Total (\%) & p-value \\
\hline \multicolumn{5}{|l|}{ 1. Changes in Chorion } \\
\hline No change & $26(38.8)$ & $41(61.2)$ & $67(81.7)$ & \multirow{3}{*}{${ }^{*}<0.05$} \\
\hline Change present & $15(100)$ & $0(0)$ & $15(13.4)$ & \\
\hline Total $(\%)$ & $41(50)$ & $41(50)$ & $82(100)$ & \\
\hline \multicolumn{5}{|l|}{ 2. Changes in amnion } \\
\hline No change & $09(18)$ & $41(82)$ & $50(61)$ & \multirow{3}{*}{${ }^{*}<0.05$} \\
\hline Change present & $32(100)$ & $0(0)$ & $32(39)$ & \\
\hline Total $(\%)$ & $41(50)$ & $41(50)$ & $82(100)$ & \\
\hline \multicolumn{5}{|c|}{ 3. Special finding: Villous Chorangiosis } \\
\hline Absent & $33(46.5)$ & $38(53.5)$ & $71(86.6)$ & \multirow{3}{*}{0.067} \\
\hline Present & $08(72.7)$ & $03(27.3)$ & $11(13.4)$ & \\
\hline Total (\%) & $41(50)$ & $41(50)$ & $82(100)$ & \\
\hline
\end{tabular}

Chorionic changes as observed in this study were mild chorio-amnionitis only.

Changes in amnion are mostly epithelial hyperplasia, meconium-laden macrophages in rare cases, other than mild chorio-amnionitis.

* Changes in chorion and amnion were statistically significant (Pearson's Chi-square test). 
calcification may be the end result of villous atrophy and fibrosis, leading to maternal and fetal hypoperfusion, is significantly associated in cases of meconium-stained liquor and associated neonatal depression ( $\mathrm{p}$ - value $<0.05$ which is statistically significant). Blood vessel changes were a noticeable finding, in this study population (Cases $=41$ ), with a significant association with both $1 \mathrm{~min}$. and $5 \mathrm{~min}$. Apgar score ( $\mathrm{p}$ - value $<0.05$; which is also statistically significant).

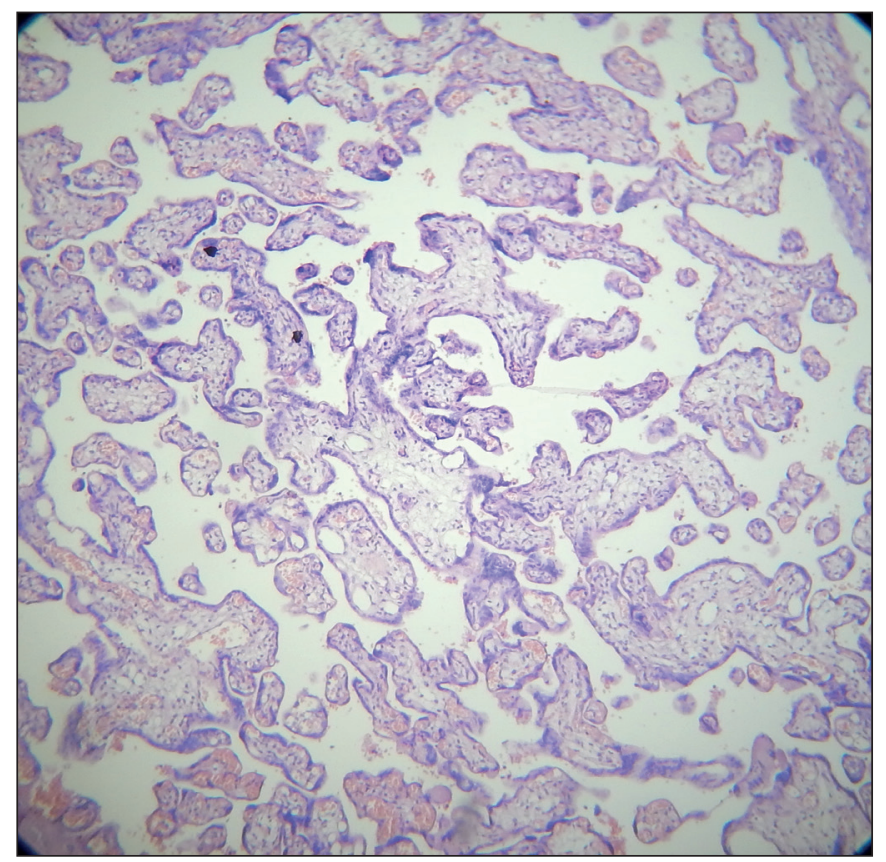

Figure 4: Normal term placenta showing primary stem villi and tertiary villi with normal inter-villous space (H\&E; x100).

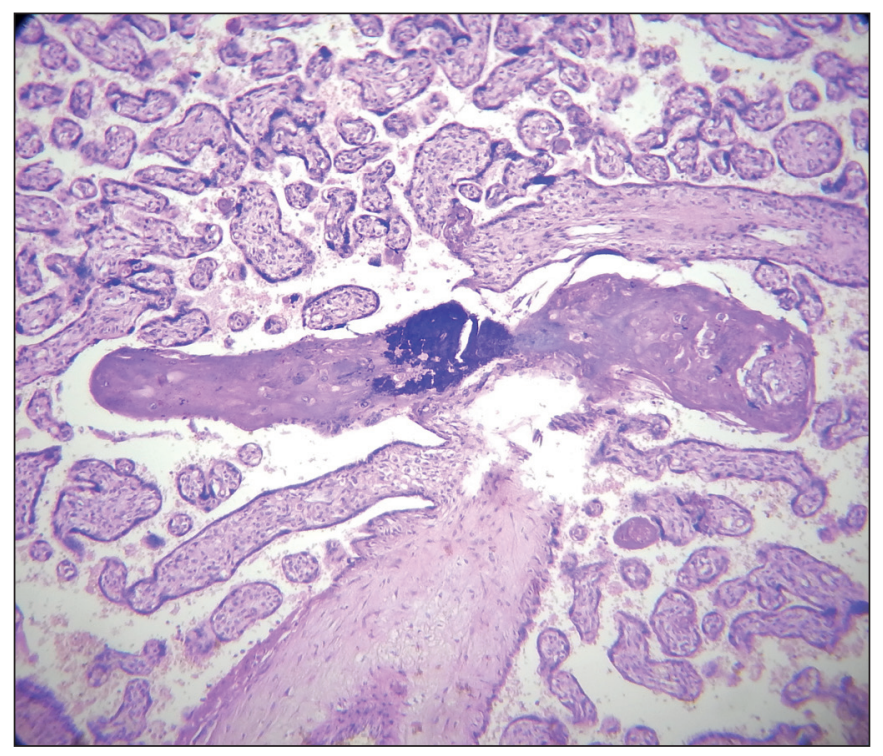

Figure 6: Intra-villous fibrinoid with calcification (H\&E; x100).
Fibro-muscular sclerosis with vascular obstruction (46.3\%) (Figure 9) was seen in a substantial population of cases $(19 / 41)$, which was statistically significant ( $p$-value $<0.05)$ finding (Table VI). We have observed that mild to severe depression were always associated with meconium stained liquor. Though this figure is statistically significant (Pearson's Chi- square test), but actually we had selected our controls as normal placenta at birth in an otherwise normal vaginal delivery. So, this finding is not significant in respect to our study population.

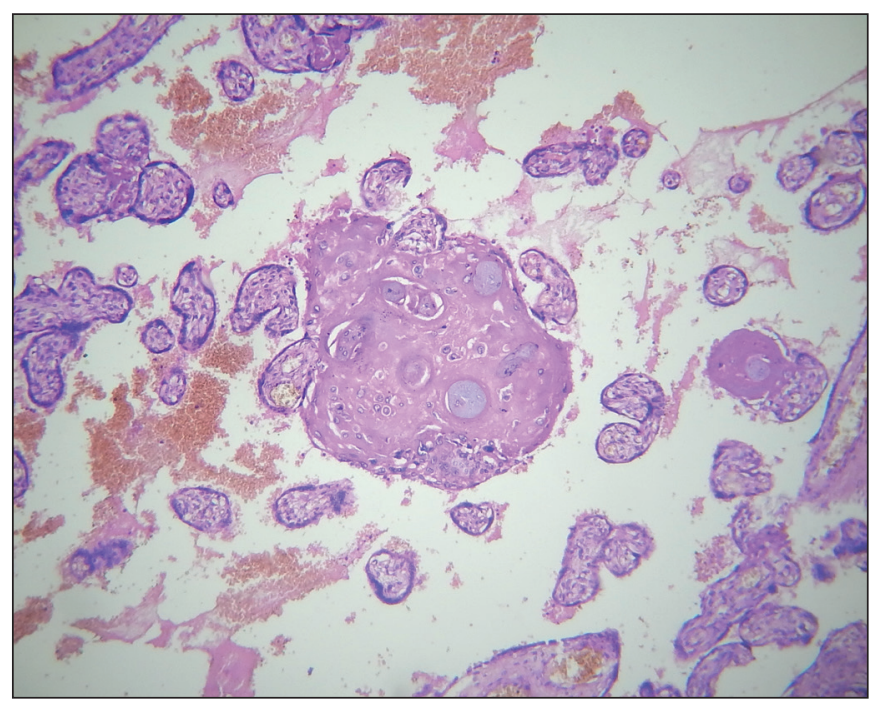

Figure 5: The increase in inter-villous space with perivillous fibrinoid (H\&E; x100).

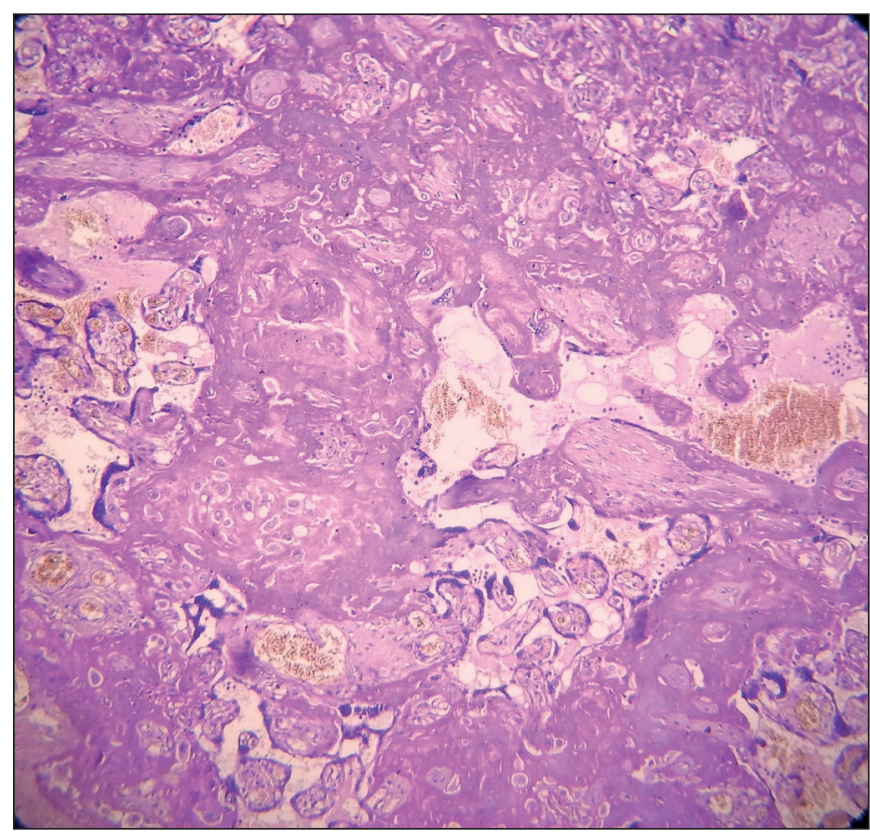

Figure 7: Extensive perivillous fibrinoid in meconium stained liquor (H\&E; $\mathrm{x} 100)$. 
Table VI: The association between different changes of placentas (macroscopical and microscopical) and Apgar score of newborns. (Chi-square test).

\begin{tabular}{lcccc}
\hline Variables & Incidence & $\begin{array}{c}\text { Depression of Apgar } \\
\text { score at one minute }\end{array}$ & $\begin{array}{c}\text { Depression of Apgar } \\
\text { score at 5 minute }\end{array}$ & p-value \\
\hline Widened intervillous space & $19.5 \%(16 / 41)$ & $19.5 \%(16 / 41)$ & $10.9 \%(9 / 41)$ & $<0.01$ \\
\hline Intra\& perivillous fibrinoid & $19.5 \%(16 / 41)$ & $14.6 \%(12 / 41)$ & $9.75 \%(8 / 41)$ & $<0.002$ \\
\hline Exagerated syncytial knots $(>5$ per villous) & $24.4 \%(20 / 41)$ & $24.4 \%(20 / 41)$ & $13.4 \%(11 / 41)$ & $<0.05$ \\
\hline Blood vessel changes & $26.8 \%(22 / 41)$ & $26.8 \%(22 / 41)$ & $13.4 \%(11 / 41)$ & $<0.05$ \\
\hline Calcification & $31.7 \%(26 / 41)$ & $31.7 \%(26 / 41)$ & $13.4 \%(11 / 41)$ & $<0.05$ \\
\hline Villous fibrosis & $13.4 \%(11 / 41)$ & $13.4 \%(11 / 41)$ & $12.2 \%(10 / 41)$ & $<0.05$ \\
\hline Epithelial hyperplasia in amnion & $7.3 \%(6 / 41)$ & $7.3 \%(6 / 41)$ & $7.3 \%(6 / 41)$ & $<0.05$ \\
\hline Changes in chorion & $39 \%(32 / 41)$ & $36.5 \%(30 / 41)$ & $13.4 \%(11 / 41)$ & $<0.05$ \\
\hline
\end{tabular}

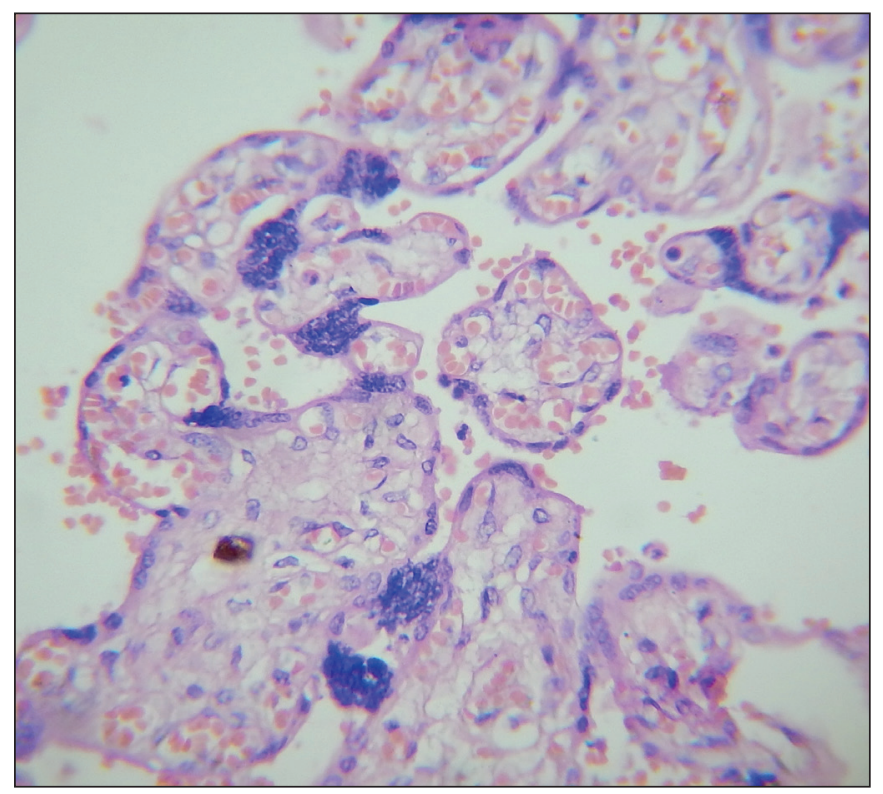

Figure 8: Exaggerated syncitial knots in meconium stained liquor (H\&E; $\mathrm{x} 400)$.

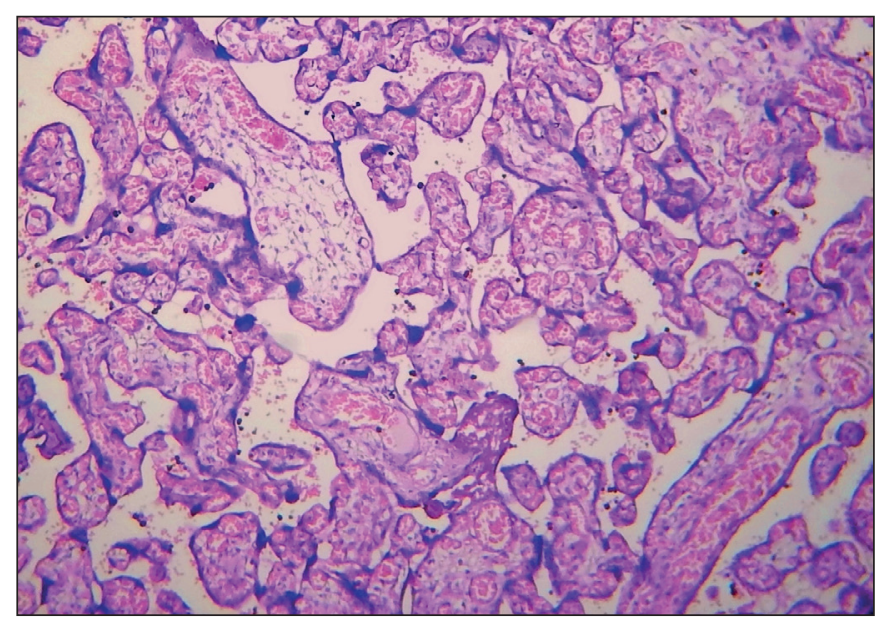

Figure 10: Villous chorangiosis in a control placenta (H\&E; $x 400)$.

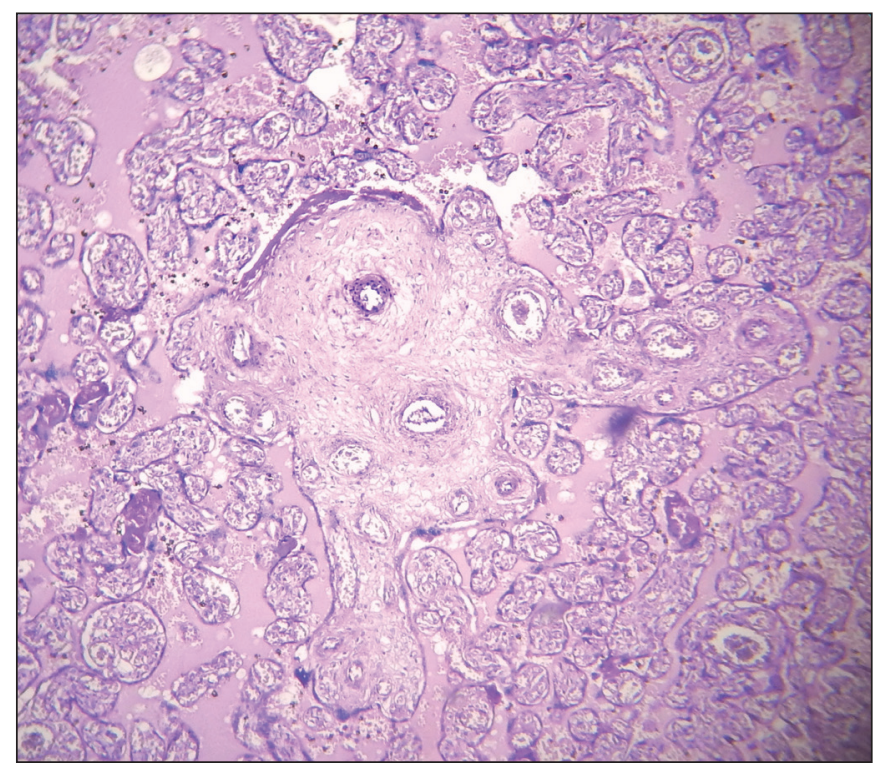

Figure 9: Fibromuscular sclerosis with intravascular fibrin thrombi (H\&E; x100).

\section{DISCUSSION}

Meconium is the bile-stained intestinal content of the fetus. It is often admixed with mucus. Meconium is present in the small bowel of fetuses long before mid-gestation but is usually not eliminated until after birth. The risk factors for meconium stained amniotic fluid are both maternal and fetal. The maternal factors are hypertension, gestational diabetes mellitus, maternal chronic respiratory or cardiovascular diseases, post term pregnancy, preeclampsia, and eclampsia. The fetal factors include oligohydramnios, intrauterine growth restriction, and poor biophysical profile (16). Meconium staining is an indicator of increased perinatal morbidity, though many cases may have normal outcome. Meconium passage has been 
significantly associated with parameters of fetal distress including low Apgar scores, umbilical artery $\mathrm{pH}$ of 7.0 or less, respiratory distress, seizures in the first $24 \mathrm{~h}$, and need for delivery room resuscitation (1). It may cause meconium aspiration syndrome, characterized by life threatening respiratory distress. Fetal distress is defined as compromise of a fetus during the antepartum period (before labor) or intrapartum period (during the birth process). The term fetal distress is commonly used to describe fetal hypoxia (low oxygen levels in the fetus), which can result in fetal damage or death if it is not reversed or if the fetus is not promptly delivered.

The mean age of the mothers in this study is 23.11 years (23.17 in the meconium group and 23.05 in the clear liquor group). There is no significant difference in the mean age between case and control population (by 2 tailed significance test the value is 0.805$)$. In this study, $46.3 \%$ of the mothers in the meconium stained liquor group (19/41) and $43.9 \%(18 / 41)$ of the mothers in the clear liquor group were primipara. So, there is similarity of parity between cases and controls. However, Osava et al. (17) found higher incidence of meconium stained liquor in primipara in comparison to clear liquor cases in their study. Klufio et al. (18) found positive significant association between grand multiparty and meconium stained liquor. In the present study, mean and most frequently occurring gestational age in both meconium and clear liquor group is 37 weeks and the average birth weight (BW) of babies is $2749.39 \mathrm{~g}$.. The mean BW in meconium group was $2818.90 \mathrm{~g}$. and in clear liquor group it is $2679.88 \mathrm{~g}$.. So, the BW is little higher in meconium group, having no statistical significance. However, Zhu et al. (20) noted in their study that birth weight was higher in meconium stained amniotic fluid group than that in clear amniotic fluid group $(\mathrm{P}<0.001)$. However, Khazardoost et al. (8) found that neonatal birth weight was lower in the meconium stained liquor cases. Odongo et al. (21), however, found no significant difference in the mean birth weights of the infants born to women in 36 meconium stained liquor cases and 41 clear liquor cases (3359.72 g. and 3260.24 g. respectively, p-value: 0.282 ). This study also showed similar results on statistical analysis. In the present study, the mean placental weight of the case population was $480.98 \mathrm{~g}$. and of the control population is $487.32 \mathrm{~g}$. In this study, we found $19.6 \%$ thin meconium liquor and $80.4 \%$ thick meconium liquor among the cases. Meconium stained liquor is associated with increased incidence of caesarean section, as noted in the studies by Arulkumaran et al. (4), Shaikh et al. (6), Osava et al. (17), Odongo et al.(21), Khatree et al. (22), and Klufio et al. (18). Similarly, in the present study, there is increased caesarean section rate among meconium stained liquor group: $29.3 \%$ delivered vaginally and $70.7 \%$ delivered by caesarean section. But, in contrast, in a study by Kumari et al. (7) $60 \%$ patients delivered through normal vaginal delivery and $40 \%$ through caesarean section among meconium stained liquor cases. Microscopically, free meconium consists of amorphous green-brown material and anucleate squames. The amniotic epithelium exposed to meconium shows degenerative changes including heaping, stratification, ballooning degeneration and eventually nuclear pyknosis and necrosis. With time, meconium is engulfed by macrophages in the amnion, chorion, and deciduas. Meconium is usually scant in the umbilical cord due to the paucity of macrophages. To investigate whether meconium causes vasoconstriction, Altshuler et al. (10) tested umbilical vein tissue with an isometric transducer connected to a polygraph. They hypothesized that meconium may cause placental and umbilical cord vasoconstriction, cerebral and other fetal hypoperfusion, and major poor outcome. According to Ziadie M.(11), meconium induced changes to placenta may be graded depending upon the exposure time of meconium mainly by the presence of meconium filled macrophages in the placental membranes. This study had shown significant association between meconium stained liquor and neonatal depression evaluated by Apgar score.

Apgar score was devised in 1952 by the eponymous Dr. Virginia Apgar as a simple and repeatable method for quickly and summarily assesses the health of newborn children immediately after birth and to diagnose fetal distress at birth (23). Apgar was an anesthesiologist who developed the score in order to ascertain the effects of obstetric anesthesia on babies. It has a continuous value in detecting fetal distress at birth for many years $(24,25)$.

From that time, numerous studies (19,26-31) have demonstrated lower 1 and 5 minute APGAR scores in cases of thick meconium and increased incidence of caeserean sections and maternal and perinatal foetal morbidity. In our study, 1 minute Apgar score shows no depression in $17.1 \%$, mild depression in $60.9 \%$ and severe depression in $22 \%$ cases of meconium stained liquor. Mild and severe depression is present in meconium stained liquor group only. All clear liquor cases (controls) have no depression. At 5 minutes Apgar score no depression was observed in $73.2 \%$ of newborns, mild depression in $24.4 \%$ and severe depression in $2.4 \%$ of meconium stained liquor. Mild and severe depression is present in meconium stained liquor cases only. These findings are statistically significant. So, both 1 and 5 minutes Apgar scores are lower (denoting depression) in meconium stained liquor group in 
comparison to clear liquor. Similarly, Misao et al. (2) noted increased incidence of low Apgar score in their study. Arulkumaran et al. (4) also found low 1 minute Apgar score and more admission of the newborns in special baby care unit. Zhu et al. (20) noted average Apgar score in meconium stained amniotic fluid group was lower than that in normal amniotic fluid group $(\mathrm{P}=0.001)$. Ramchandra et al. (5) found higher incidence of low Apgar score (0-7) at one minute in study group as compared to the control, but no significant difference was found in the Apgar score at 5 minutes.

A significant association was also noted between Apgar score and several microscopical changes in placentas of meconium stained liquor.

When association between Apgar score (both at 1 and 5 minutes) and placental changes are assessed, it is seen that color of placenta, color of membrane and most of the microscopical changes noted here, are significantly higher in meconium group in comparison to clear group, except villitis and infarction. Most changes are related to villous structures. These are increase in intervillous space, intravillous fibrinoid, perivillous fibrinoid, calcification, fibrosis, syncytial knots, blood vessel changes (especially, fetal thrombotic vasculopathy). These changes are statistically significant ( $\mathrm{p}$ - value: $<0.05$ ) in meconium stained liquor group in comparison to clear liquor group. Though, villitis (6.1\%) and infarction (1.2\%) are not statistically significant (p-value: $>0.05$ ) in this study. No change was noted in umbilical cord both in control group and cases.

In the fetal membrane, (i.e.: amnion and chorion) we found multi-layering of amniotic epithelium in significant number of the cases (Amnion epithelial hyperplasia) and chorio-amnionitis in 15 cases, which are statistically significant findings ( $\mathrm{p}$ - value: $<0.05$ ) in meconium group in comparison to clear liquor group. However, meconium laden macrophages in amnion or chorion are noted in only 3 cases of meconium stained liquor, may be because of early intervention in a tertiary care center. Necrosis or ballooning degeneration of chorion and amnion are not found in any cases of study population. Villous chorangiosis is a peculiar finding in this study. It is present in $13.4 \%$ of total cases ( $72.7 \%$ in meconium stained liquor group and $27.3 \%$ in clear liquor group). But the finding is not statistically significant (p- value: $0.067(>0.05)$ ). But, Altshuler (32) found it to be a sign of neonatal morbidity and mortality. A study by Kaspar et al. (33), described 9 different pathologic lesions of the placenta. Among those, the frequency of villous vascular thrombosis (25.4\%), infarcts (38\%), acute chorioamnionitis (20\%), villous edema (9.1\%) and villitis (14.5\%) was significantly higher in the group with longer meconium exposure. Somewhat closely we have also found many changes in villi. Though in our study, villous oedema is not present; villitis and infarction are not significant finding in the present study. Kariniemi et al. (34) found that meconium in the amniotic fluid seem to be associated with placental rather than with umbilical insufficiency. In this study we also found similar type of findings.

This study also suggests, that vascular changes in villous structures are possibly present due to placental insufficiency, causal factor for fetal distress and meconium passage, either due to maternal or due to fetal hypoperfusion, and not the effect of long standing meconium exposure. Redline et al. (35), Sienko and Altshuler (36), Altshuler et al. (37), demonstrated muscle necrosis of umbilical vessels with prolonged meconium exposure. Ziadie (11) described meconium laden pigmented macrophages with apoptotic like nuclei present in different parts of placenta. However, this study did not show this type of microscopical feature, significantly. We found more changes in villi, fewer changes in amnion and chorion, no change in umbilical cord at all. It had previously been observed that intra-uterine fetal distress is the consequences of maternal and fetal vascular compromise, though the normal placenta has considerable functional reserve (1). This study also revealed that various placental changes observed in meconium stained liquor and associated neonatal outcome are mostly the features of fetal thrombotic vasculopathy as well as fetal and maternal hypoperfusion. Intra-villous and peri-villous fibrinoid, increase inter-villous space, fibro-muscular sclerosis of fetal vessels with or without calcification and luminal obstruction as observed in this study are the features of vascular compromise.

In conclusion, we can postulate that, villi changes of placenta, most importantly arises out of vascular compromise in villi may be the primary cause which gives rise to fetal distress and thereby passage of meconium in utero, possibly arises out of chronic placental hypoxia. Fetal thrombotic vasculopathy, characterized by increased intra- and peri- villous fibrinoid, exaggerated syncytial knots, villous fibrosis and fibro-muscular sclerosis may be the cause behind chronic placental hypoxia. The changes which are described in various studies, like changes in umbilical cord and fetal membrane are not present in this study, may be due to early intervention of the meconium stained liquor cases and thus changes associated with chronic meconium exposure were not detected in this small study group. Elaborate cross-sectional study is necessary 
for further comments regarding placental changes in meconium exposure with time and its effect on neonatal outcome.

\section{ACKNOWLEDGEMENT}

The authors thank all staffs of Department of Pathology, Burdwan Medical College for support and help in this research work.

\section{FUNDING}

The authors confirm that they are all employee of Government of West Bengal, India and have no corporate affiliations. No funding has been received to do this research work.

\section{CONFLICT of INTEREST}

The authors declare no conflict of interest.

\section{REFERENCES}

1. Gersell DJ, Kraus FT. Diseases of placenta. In: Kurman RJ, Ellenson LH, Ronnett BM, editors. Blaustein's Pathology of the female genital tract. 6th ed. New York: Springer; 2011. 999- 1074.

2. Misao S, Yoshie H, Shunji S. Perinatal outcomes associated with meconium-stained amniotic fluid in Japanese singleton pregnancies. OJOG. 2011; 1: 42-6.

3. Espinheira MC, Grilo M, Rocha G, Guedes B, Guimarães H. Meconium aspiration syndrome - the experience of a tertiary center. Rev Port Pneumol. 2011; 17:71-6.

4. Arulkumaran S, Yeoh SC, Gibb DM, Ingemarsson I, Ratnam SS. Obstetric outcome of meconium stained liquor in labour. Singapore Med J. 1985;26:523-6.

5. Ramachandra FL, BhargavaVL, Pmade Y, Goel FL. Significance of meconium during labour and its correlation with umbilical cord blood studies. Indian J Pediatr. 1984;51:149-53.

6. Shaikh EM, Mehmood S, Shaikh MA. Neonatal outcome in meconium stained amniotic fluid-one year experience. J Pak Med Assoc. 2010;60:711-4.

7. Kumari R, Srichand P, Devrajani BR, Shah SZ, Devrajani T, Bibi I, Kumar R. Fetal outcome in patients with meconium stained liquor. J Pak Med Assoc. 2012; 62:474-6.

8. Khazardoost S, Hantoushzadeh S, Khooshideh M, Borna S. Risk factors for meconium aspiration in meconium stained amniotic fluid. J Obstet Gynaecol. 2007; 27:577-9.

9. Cleary GM, Wiswell TE. Meconium-stained amnionic fluid and the meconium aspiration syndrome. An update. Pediatr Clin North Am. 1998; 45:511-29.

10. Altshuler G, Hyde S. Meconium-Induced Vasocontraction: A potential cause of cerebral and other fetal hypoperfusion and of poor pregnancy outcome. J Child Neurol. 1989; 4:137-42.

11. Ziadie, M. Placental development. PathologyOutlines. com website. http://www.pathologyoutlines.com/topic/ placentaplacentaldevel.html. Accessed April 21st, 2018
12. Chapman S, Duff P. Incidence of chorioamnionitis in patients with meconium-stained amniotic fluid. Infect Dis Obstet Gynecol. 1995; 2:210-2.

13. Yetter JF. Examination of the placenta. Am Fam Physician. 1998;57:1045-54.

14. Benirschke K, Kaufmann P, Baergen RN. Pathology of the human placenta. 5th ed. New York: Springer Science \& Business Media; 2006.

15. Baergen RN. Manual of Benirschke and Kaufmann's pathology of the human placenta. New York, NY: Springer Science \& Business Media; 2005.

16. Hackey WE. Meconium aspiration. In; Gomella TL. Neonatology. 4th ed. Newyork: Lange Medical Books; 1999. 507.

17. Osava RH, Da Silva FM, Vasconcellos de Oliveira SM, Tuesta EF, Do Amaral MC. Meconium-stained amniotic fluid and maternal and neonatal factors associated. Rev Saude Publica. 2012; 46:1023-9.

18. Klufio CA, Amoa AB, Kariwiga G, Rageau O. A case-control study of meconium staining of amniotic fluid in labour at Port Moresby General Hospital to determine associated risk factors and perinatal outcome. P N G Med J. 1996; 39:297-309.

19. Erkkola R, Kero P, Suhonen-Polvi H. Meconium aspiration syndrome. Ann Chir Gynaecol Suppl. 1994; 208:106-9.

20. Zhu L, Zhongguo Yi, Xue Ke, Xue Yuan, Xue Bao. The epidemiology of meconium stained amniotic fluid on hospital basis. Zhongguo Yi Xue Ke Xue Yuan Xue Bao. 2003;25:63-5.

21. Odongo BE, Ndavi PM, Gachuno OW, Sequeira E. Cardiotocography and perinatal outcome in women with and without meconium stained liquor. East Afr Med J. 2010;87:199204.

22. Khatree $\mathrm{MH}$, Mokgokong ET. The significance of meconium staining of the liquor amnii during labour. S Afr Med J. 1979;56:1099-101.

23. Apgar V. A proposal for a new method of evaluation of the newborn infant. Curr Res Anesth Analg 1953;32: 260-7.

24. Casey BM, McIntire DD, Leveno KJ. The continuing value of the Apgar score for the assessment of newborn infants. N Engl J Med. 2001;344:467-71.

25. Finster M, Wood M. The apgar score has survived the test of time. Anesthesiology. 2005;102:855-7.

26. Mahomed K, Nyoni R, Masona D. Meconium staining of the liquor in a low-risk population. Paediatr Perinat Epidemiol. 1994;8:292-300.

27. Meis PJ, Hobel CJ, Ureda JR. Late meconium passage in labor--a sign of fetal distress? Obstet Gynecol. 1982;59:332-5.

28. De Souza SW, John RW, Richards B, Milner RD. Fetal distress and birth scores in newborn infants. Arch Dis Child. 1975;50: 920-6.

29. Gupta V, Bhatia BD, Mishra OP. Meconium stained amniotic fluid: Antenatal, intrapartum and neonatal attributes. Indian Pediatr J. 1996;33:293-7.

30. Ahanya SN, Lakshmanan J, Morgan BL, Ross MG. Meconium passage in utero: Mechanisms, consequences, and management. Obstet Gynecol Surv. 2005; 60:45-56. 
31. Lucas GN, Dissanayake P. A study of meconium staining and meconium aspiration syndrome in a maternity hospital. Ceylon Med J. 1995;40:62-3.

32. Altshuler G. Chorangiosis. An important placental sign of neonatal morbidity and mortality. Arch Pathol Lab Med. 1984;108:71-4.

33. Kaspar HG, Abu-Musa A, Hannoun A, Seoud M, Shammas M, Usta I, Khalil A. The placenta in meconium staining: Lesions and early neonatal outcome. Clin Exp Obstet Gynecol. 2000; 27:63-6.

34. Kariniemi V, Harrela M. Significance of meconium staining of the amniotic fluid. J Perinat Med. 1990; 18:345-9.
35. Redline RW, O’ Riordan MA. Placental lesions associated with cerebral palsy and neurologic impairment following term birth. Arch Pathol Lab Med. 2000; 124:1785-91.

36. Sienko A, Altshuler G. Meconium-induced umbilical vascular necrosis in abortuses and fetuses: A histopathologic study for cytokines. Obstet Gynecol. 1999; 94:415-20.

37. Altshuler G, Arizawa M, Molnar-Nadasdy G. Meconium-induced umbilical cord vascular necrosis and ulceration: A potential link between the placenta and poor pregnancy outcome. Obstet Gynecol. 1992;79:760-6. 